\title{
Travel Incheon as a Metaverse: Smart Tourism Cities Development Case in Korea
}

\author{
Taehyee Um(D), Hyunkyu Kim (D), Hyunji Kim (D), Jungho Lee (D), \\ Chulmo Koo (D), and Namho Chung ${ }^{(\bowtie)}(\mathbb{D}$ \\ Smart Tourism Education Platform, Kyung Hee University, Seoul, South Korea \\ \{thum, hkk3405, hyunjik, lee-jung-ho, helmetgu, \\ nhchung\}@khu.ac.kr
}

\begin{abstract}
The central government and local governments of the South Korea execute a project to build smart tourism city for tourism and urban development. However, little study has shed light on the details of smart tourism city project. To approach the concept of smart tourism city and understand the phenomenon of smart tourism city construction, this study conducts a case study. Incheon is the first city in which implementing the smart tourism city creation project. We apply the metaverse concept to check how Incheon implements a smart tourism city. Specifically, the metaverse concept applied tourism service operated by Incheon is divided into real based and virtual based (AR Incheon and Incheoncraft). Along with an introduction to the case, how the concept of metaverse supports the creation of a smart tourism city is discussed. This is an early-stage study that explores the phenomenon by considering the relationship between the smart tourism and metaverse.
\end{abstract}

Keywords: Smart tourism city $\cdot$ Metaverse $\cdot$ Incheon open port

\section{Introduction}

A city's ICT (Information and communication technology) infrastructure can play an important role in making the city competitive in tourism [14]. The central government and local governments in South Korea are operating a project to build a smart tourism city based on ICT to revitalize local tourism. The number of organizations applying for the project increased by more than $33 \%$ in 2021 compared to last year [9]. Research related to smart cities and smart tourism has been conducted in a variety of ways since the early 2000s. However, research on smart tourism city remains in its infancy [11]. Therefore, it is necessary to conduct research to understand the current status of urban development projects applying the concept of a smart tourism city. Incheon is the first selected area in South Korea to create a smart tourism city, providing services, content, and information for smart tourism to tourists. In addition, Incheon is making efforts to overcome the spatial limitation that a smart tourism city requires a physical space. As part of this effort, it also developed contents that applied metaverse concept. This study will conduct case studies for services to create smart tourism cities in the physical environment of Incheon open port and virtual spaces as a metaverse. 


\section{Literature Review}

\subsection{Smart Tourism City}

Smart tourism city is semantically the combination of the three words: smart, tourism, city. 'Smart' is a buzzword that describes the technology integration in various sectors serving to enhance efficiency and convenience. 'Smart tourism' is an application of 'smart' in the tourism sector, allowing a technology-oriented on-site tourism experience at a destination [5]. 'Smart tourism city' is a city that facilitates smart tourism to offer innovative tourism destinations with sustainable development [11]. Although the term smart tourism city seems to be the technical sum of three separate words, its definition is not confined to the mere integration of technology in tourism and the city. Smart tourism city pursues the ideal form of tourism destination, not only providing tourists with convenient experiences but also aiming to enhance the residents' quality of life which sustains the ecosystem [5]. In this regard, smart tourism city is oriented toward a similar goal with smart city, which represent up-and-coming city fueled by digital technologies to optimize resource efficiency, improving the quality of life of all residents [14]. Smart tourism city can be considered a specialized concept, operating upon the technological and theoretical foundations that the smart city provides, but mainly focused on the innovativeness of the tourism sector. Therefore, smart tourism city is particularly concerned with integrating technology into tour-related realms, which enhance the enjoyment of tourist attractions and provide easy accessibility to the destination [4]. Meanwhile, the recent development of virtualization technology makes it possible for tourists to experience smart tourism city in the virtual world, allowing them to enjoy the attractions regardless of physical accessibility. This new shift in the tourism sector can be explained by the term metaverse.

\subsection{Metaverse}

Metaverse, a 3D virtual world where people can experience a social/economic environment same as the real world $[6,13]$, has recently gained explosive attention in tourism industry as physical movement and human touching are restricted in COVID19 pandemic. Metaverse was commercialized as Second Life, a social virtual world game in 2003, 10 years after its first appearance in Snow Crash of Neal Stephenson in $1992[6,13]$. However, it was virtually impossible for individuals and companies to actively engage in metaverse due to the limitations of the ICT level and the lack of public interest. Only today, active engagement is realized through smartphone and Wi$\mathrm{Fi}$, which allow people to access the metaverse freely [10, 14].

Metaverse based on hyper-connection not only satisfies the human instinct for social interaction and embodies experience of the real world but provides a transcendent space where people can express themselves through avatars, a new self, different from oneself in the real world [13]. The transcendental characteristics of metaverse plays a role of trigger that let various fields, such as tourism, marketing, and education, recognize metaverse as a new business model $[1,8]$. Thus, over the past few decades, the scope of business has expanded from offline to website-based online, and now it is expanding once again from website to metaverse. 


\subsection{Smart Tourism with Metaverse}

Smart Tourism City strives to provide improved attractiveness and accessibility of the city by gradually expanding tourists' experiences that have been provided based on the city's ICT infrastructure into real and virtual-based metaverse [11, 12]. Metaverse basically shares the concept of 'convergence of real and virtual world', but depending on which world is focused on more, it can be divided into real-based and virtual-based metaverse [2]. A real-based metaverse focuses on the real world and reinforces the experience in the real world through virtual technology. A mirror world (e.g., google earth), a thorough replication of the real world, and Augmented Reality (AR) adopted in museums (e.g., Casa Batlló AR) can be understood as the real-based metaverse [2]. On the other hand, a virtual-based metaverse provides a novel experience that unfolds in the virtual spaces are separated from the real world. It includes a lifelogging, including social media to share tourism experiences in a virtual space, and a virtual world that allows the individuals to participate in the experience as an avatar [2].

Specifically, the two metaverse types have different characteristics according to their Role, Location of experiences, Type of Interaction, and Form of ego (see Table 1). These different types of metaverse can be utilized in the smart tourism city to overcome the physical accessibility and provide tourists with vivid tourism experiences through online. Despite the metaverse's potential and growing popularity, the existing studies only suggest a vague image of how it can be applied to the tourism sector [7]. Therefore, this study aims to introduce the case of Incheon, the leading smart tourism city in Korea, initiating various forms of metaverse for an enhanced tourism experience by focusing on each characteristic suggested in Table 1.

Table 1. Real-based vs. virtual-based: revealing the differences

\begin{tabular}{l|l|l}
\hline & Real-based metaverse & Virtual-based metaverse \\
\hline Role of metaverse & Reinforcing real experiences & Providing new experiences \\
\hline Location of experiences & Physical world & Virtual world \\
\hline Type of Interaction & One-way & Two-way \\
\hline Form of ego & Same as the real self & A new self-made by a user \\
\hline
\end{tabular}

Source: Authors

\section{Case Study}

Incheon is a metropolitan city in the northwest of South Korea. Incheon open port is a tourist destination, with many modern historical cultural assets preserved around the time of Incheon's opening in the late 19th century. Incheon open port is currently developing smart tourism city through building smart eco-system, environment, and experience. In this paper, we will introduce two main metaverse service provided by Incheon through 'Incheon Easy' smart tourism application. 


\subsection{Real-Based Metaverse - 'AR Incheon'}

$\mathrm{AR}$, augmented reality is generally defined as reinforced real experience provided by computer-generated images through digital devices, based on the physical world environment [3]. Unlike virtual reality metaverse 'Incheoncraft', AR services designed by Incheon provides one-way interactive contents by smartphone camera, letting tourists experience AR in real-world as themselves through usage of AR application, increasing tourism attractiveness.

AR service in Incheon is more than other simple AR services such as delivery of information through digital display, description, and guide contents which most smart cities and museums provide. It provides AR navigation service and AR map, but it is differentiated by providing historic maps and experiences from the past. It engages the users in the environment(real-world), providing extended reality experience, such as environment-related historic figures guiding the tourists, panoramic virtual mirror world through AR where tourists can share experiences on social network, seamlessly connecting real-world based and virtual world based metaverse. Lastly, there is a gamified service 'Operation Incheon' which gives missions to tourists, engaging in the service by providing incentives through clearing them.

\subsection{Virtual-Based Metaverse - 'Incheoncraft'}

Incheon developed metaverse entertainment content which provide 'Incheon experience' through using Minecraft. Integrating Minecraft, a sandbox game which players explore a virtual world freely as avatars. This enabled users to create and experience Incheon without limits in the metaverse world, allowing Incheon to deliver the smart metaverse experience to tourists without their physical visit. There are examples of indirect experiences through Minecraft such as 'English Heritage' providing 'mirror world' experience without interactions. However, Incheon wanted to provide memorable experience which is impossible to be experienced in the real world through full 'virtual world' experience. The solution was to provide more than the city's façade, through virtual time-travel in Incheon interacting as an avatar; a new-self made by the user, with other players' avatars. In 'Incheoncraft', users can experience historic events with historic figures, and learn educational facts in Incheon metaverse (see Fig. 1).

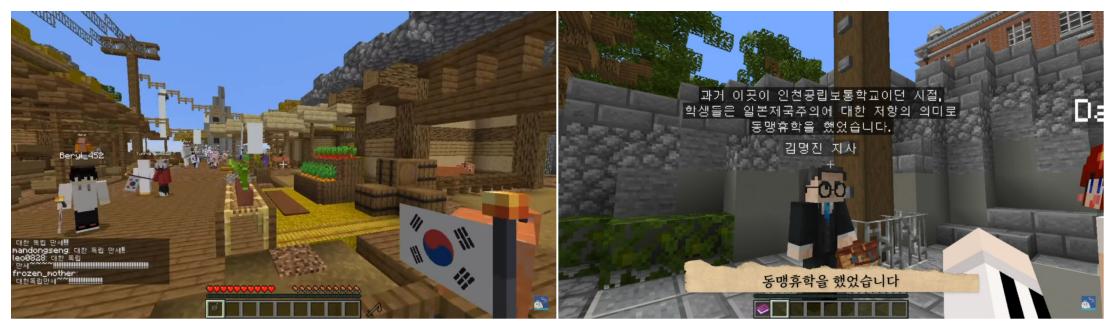

Fig. 1. Players in 'Incheoncraft' experiencing historic event 


\section{Conclusion}

This study tried to understand the phenomenon of smart tourism cities adopting metaverse, which are still in the early stages of research, through a case study. In particular, a study was conducted to introduce contents that could enhance the tourists' experience and increase accessibility to the Incheon area beyond the limitations of location-based services through metaverse. Through this study, we were able to form a link between the concept of metaverse and smart tourist cities that have rarely been discussed before. To the best of our knowledge, this is the first attempt to shed light on tourism in conjunction with metaverse, provided with a tangible case study. In addition to this novel first step, this study paved the way to discuss the current smart tourism cities in respect of the metaverse, opening the door for future studies to explore the interplay of the two subjects.

\section{References}

1. Alcañiz M, Bigné E, Guixeres J (2019) Virtual reality in marketing: a framework, review, and research agenda. Front Psychol 10:1530

2. Ane BK, Roller D, Lolugu J (2019) Ubiquitous virtual reality: the state-of-the-art. Int J Comput Sci Mob Comput 8(7):16-26

3. Carmigniani J, Furht B (2011) Augmented reality: an overview. In: Furht B (ed) Handbook of augmented reality. Springer, New York, pp 3-46. https://doi.org/10.1007/978-1-46140064-6_1

4. Chung N, Lee H, Ham J, Koo C (2021) Smart tourism cities' competitiveness index: a conceptual model. In: Wörndl W, Koo C, Stienmetz JL (eds) Information and communication technologies in tourism 2021. Springer, Cham, pp 433-438. https://doi.org/10.1007/ 978-3-030-65785-7_42

5. Gretzel U, Sigala M, Xiang Z, Koo C (2015) Smart tourism: foundations and developments. Electron Mark 25(3):179-188. https://doi.org/10.1007/s12525-015-0196-8

6. Hendaoui A, Limayem M, Thompson CW (2008) 3D social virtual worlds: research issues and challenges. IEEE Internet Comput 12(1):88-92

7. Huang YC, Backman KF, Backman SJ, Chang LL (2016) Exploring the implications of virtual reality technology in tourism marketing: an integrated research framework. Int J Tour Res 18(2):116-128

8. Jung T, tom Dieck MC, Lee H, Chung N (2016) Effects of virtual reality and augmented reality on visitor experiences in museum. In: Inversini A, Schegg R (eds) Information and communication technologies in tourism 2016. Springer, Cham, pp 621-635. https://doi.org/ 10.1007/978-3-319-28231-2_45

9. KTO. https://kto.visitkorea.or.kr/viewer/view.kto?id=73869\&type=bd. Accessed 20 Mar 2021

10. Kwok AOJ, Koh SGM (2021) COVID-19 and extended reality (XR). Curr Issue Tour 24 (14):1935-1940

11. Lee P, Hunter WC, Chung N (2020) Smart tourism city: developments and transformations. Sustainability 12(10):3958 
12. Lee P, Zachb FJ, Chungc N (2021) Progress in smart tourism 2010-2017: a systematic literature review. J Smart Tour 1(1):19-30

13. Smart JM, Cascio J, Paffendorf J (2007) Metaverse roadmap overview. accelerated studies foundation. http://metaverseroadmap.org. Accessed 29 Aug 2021

14. Um T, Chung N (2021) Does smart tourism technology matter? Lessons from three smart tourism cities in South Korea. Asia Pac J Tour Res 26(4):396-414

Open Access This chapter is licensed under the terms of the Creative Commons Attribution 4.0 International License (http://creativecommons.org/licenses/by/4.0/), which permits use, sharing, adaptation, distribution and reproduction in any medium or format, as long as you give appropriate credit to the original author(s) and the source, provide a link to the Creative Commons license and indicate if changes were made.

The images or other third party material in this chapter are included in the chapter's Creative Commons license, unless indicated otherwise in a credit line to the material. If material is not included in the chapter's Creative Commons license and your intended use is not permitted by statutory regulation or exceeds the permitted use, you will need to obtain permission directly from the copyright holder.

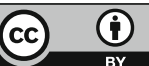

